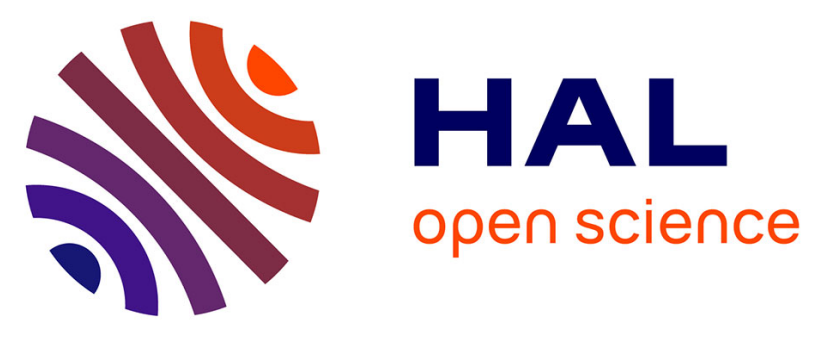

\title{
Non-HLA agonistic anti-angiotensin II type 1 receptor antibodies induce a distinctive phenotype of antibody-mediated rejection in kidney transplant recipients
}

Carmen Lefaucheur, Denis Viglietti, Yassine Bouatou, Aurélie Philippe, Daniele Pievani, Olivier Aubert, Jean-Paul Duong van Huyen, Jean-Luc Taupin, Denis Glotz, Christophe Legendre, et al.

\section{- To cite this version:}

Carmen Lefaucheur, Denis Viglietti, Yassine Bouatou, Aurélie Philippe, Daniele Pievani, et al.. Non-HLA agonistic anti-angiotensin II type 1 receptor antibodies induce a distinctive phenotype of antibody-mediated rejection in kidney transplant recipients. Kidney International, 2019, 96, pp.189 201. 10.1016/j.kint.2019.01.030 . hal-03484935

\author{
HAL Id: hal-03484935 \\ https://hal.science/hal-03484935
}

Submitted on 20 Dec 2021

HAL is a multi-disciplinary open access archive for the deposit and dissemination of scientific research documents, whether they are published or not. The documents may come from teaching and research institutions in France or abroad, or from public or private research centers.
L'archive ouverte pluridisciplinaire HAL, est destinée au dépôt et à la diffusion de documents scientifiques de niveau recherche, publiés ou non, émanant des établissements d'enseignement et de recherche français ou étrangers, des laboratoires publics ou privés.

\section{(ㄷ)(1) $\$$}

Distributed under a Creative Commons Attribution - NonCommerciall 4.0 International 
[QUERY TO AUTHOR: title and abstract rewritten by Editorial Office - not subject to change]

Non-HLA Agonistic Anti-Angiotensin II Type 1 Receptor Antibodies Induce a Distinctive Phenotype of Antibody-mediated Rejection in Kidney Transplant Recipients

Carmen Lefaucheur ${ }^{1,2}$, Denis Viglietti ${ }^{1,2}$, Yassine Bouatou ${ }^{1,3}$, Aurélie Philippe ${ }^{4}$, Daniele Pievani $^{1,2}$, Olivier Aubert ${ }^{1,5}$, Jean-Paul Duong Van Huyen ${ }^{1,6}$, Jean-Luc Taupin ${ }^{7}$, Denis Glotz ${ }^{1,2}$, Christophe Legendre ${ }^{1,5}$, Alexandre Loupy ${ }^{1,5}$, Philip F Halloran ${ }^{8,}$, , Duska Dragun ${ }^{4,}$

${ }^{1}$ Paris Translational Research Center for Organ Transplantation, INSERM, UMR-S970, Paris, France, ${ }^{2}$ Kidney Transplant Department, Saint-Louis Hospital, Assistance Publique - Hôpitaux de Paris, Paris, France; ${ }^{3}$ Division of Nephrology, Geneva University Hospitals, Geneva, Switzerland; ${ }^{4}$ Clinic for Nephrology and Critical Care Medicine, Campus Virchow-Klinikum and Center for Cardiovascular Research, Medical Faculty of the Charité Berlin, Berlin, Germany; ${ }^{5}$ Kidney Transplant Department, Necker Hospital, Assistance Publique - Hôpitaux de Paris, Paris, France; ${ }^{6}$ Pathology Department, Necker Hospital, Assistance Publique - Hôpitaux de Paris, Paris, France; ${ }^{7}$ Department of Immunology and Histocompatibility, Saint-Louis Hospital, Assistance Publique - Hôpitaux de Paris, Paris, France; ${ }^{8}$ Alberta Transplant Applied Genomics Center, University of Alberta, Edmonton, $A B$, Canada

${ }^{*}$ Co-senior authorship

\section{Corresponding author}

Pr. Carmen Lefaucheur

Paris Translational Research Center for Organ Transplantation, Institut national de la santé et de la recherche médicale, Unité mixte de recherche-S970, Paris, France

Email: carmen.lefaucheur@wanadoo.fr

Phone: +33 153988000 Fax: +33 142494653

Keywords: allograft survival, angiotensin II type 1 receptor antibody, antibody-mediated rejection, kidney transplantation

Running title: AT1R antibodies in kidney recipients

Word count: 4032

Tables: 5

Figures: 3 


\section{ABSTRACT}

Anti-angiotensin II type 1 receptor (AT1R) antibodies have been associated with allograft rejection. We hypothesized that circulating AT1R antibodies might identify kidney transplant recipients at increased risk of allograft rejection and loss who are not identified by the HLA system. We prospectively enrolled 1845 kidney transplant recipients from two centers. Donor-specific HLA antibodies (DSAs) and AT1R antibodies were measured at the time of the first acute rejection episode or at 1 year post-transplant. Allograft biopsy was performed to evaluate the rejection phenotype and to assess for endothelial activation. Overall, 371 (20.1\%) participants had AT1R antibodies, $334(18.1 \%)$ had DSAs, and $133(7.2 \%)$ had both. AT1R antibodies were associated with an increased risk of allograft loss (adjusted HR 1.49, 95\% CI 1.07-2.06 for AT1R antibodies alone and 2.26, 95\% CI 1.52-3.36 for AT1R antibodies and DSAs). Participants with AT1R antibodies had a higher incidence of antibody-mediated rejection (AMR) compared with participants without AT1R antibodies (25.0\% vs. 12.9\%). Among 77 participants with histological features of AMR but without DSAs, 51 (66.2\%) had AT1R antibodies. Compared to participants with prototypical DSA-mediated rejection, those with AT1R antibody-associated rejection had higher prevalence of hypertension, more vascular rejection with arterial inflammation, higher levels of endothelial-associated transcripts, and lack of complement deposition in allograft capillaries. Thus, AT1R antibodies may identify kidney transplant recipients at high risk of allograft rejection and loss, independent of the HLA system. Recognition of complement-independent AT1R antibody-mediated vascular rejection could lead to the development of new treatment strategies to improve allograft survival. 


\section{INTRODUCTION}

Incompatibility between genetically disparate donor and recipient pairs has been recognized as the fundamental contributing factor to allograft rejection, which is a main impediment to successful transplantation of various organs, including kidney, ${ }^{1}$ heart, ${ }^{2}$ lung $^{3}$ and liver. ${ }^{4}$ Allograft rejection mainly occurs through the triggering of donor-specific immune responses mediated by $T$ and B cells. ${ }^{5}$ The Human Leucocyte Antigen (HLA) tissue system has been identified as the primary target of donor-specific alloimmune responses, especially by involving recipient production of antibodies directed towards non-self-donor HLA class I and HLA class II proteins that are expressed on the allograft endothelium and show high polymorphism. ${ }^{6}$ The assessment of the HLA system, which consists of measuring the degree of HLA class I and HLA class II tissue antigen matching between the recipient and the donor and then detecting circulating donor-specific anti-HLA antibodies (DSAs) in the recipient's serum, represents the contemporary gold standard for defining patients' access to transplantation, post-transplant immunological monitoring and allograft rejection diagnosis. ${ }^{6,7}$ However, it is commonly acknowledged that this HLA-centric approach does not provide a sufficient level of accuracy for the evaluation of immunological complications in transplant recipients. ${ }^{7}$ Accumulating evidence has highlighted that allograft rejection with pathological features of antibodymediated rejection can occur in patients without detectable anti-HLA DSAs using highly sensitive contemporary assays, ${ }^{8}$ even in recipients of transplants from HLA-identical siblings. ${ }^{9}$

The allograft endothelium represents the first barrier between the transplanted organ and the immune system of the recipient; this endothelium expresses the most potentially relevant antigens in transplant immunobiology..$^{5}$ Among antibodies to non-HLA endothelial antigens, agonistic antibodies directed towards angiotensin II type 1 receptor (AT1R), a G-protein coupled receptor that is expressed at the endothelial cell surface, have been the most 
commonly reported non-HLA antibodies that are associated with allograft rejection. The presence of anti-AT1R antibodies in transplant recipients was initially reported in 16 patients with steroid-refractory vascular rejection ${ }^{10}$ and was further associated in small studies with the occurrence of allograft dysfunction, rejection or loss in adult and pediatric kidney, ${ }^{11-23}$ heart, ${ }^{24}$ lung $^{25}$ and liver ${ }^{26}$ transplant recipients. However, these findings have not been reproduced by other investigators, who reported a lack of association between anti-AT1R antibodies and allograft outcomes or associations limited to patients with concomitant anti-HLA DSAs, ${ }^{27-30}$ particularly in the largest study conducted to date. ${ }^{31}$ Therefore, the impact of anti-AT1R antibodies on transplant outcomes at the population level, with respect to the presence of concomitant anti-HLA antibodies and to what extent they can induce allograft rejection independently and/or synergistically with anti-HLA antibodies, remains largely unclear. Given the low level of evidence linking anti-AT1R antibodies to allograft rejection and loss at the population level, screening for these antibodies is neither considered standard of care for risk stratification and monitoring of allograft rejection by international guidelines $7,32,33$ nor for the diagnosis of allograft rejection by international classifications. ${ }^{34-37}$

We sought to determine, in a large, prospective cohort of well-phenotyped kidney transplant recipients, whether post-transplant circulating anti-AT1R antibodies might play a role in the failure of kidney allografts and to what extent their detection might identify patients at risk of allograft rejection and loss who are unrecognized by current diagnostic standards based on HLA assessment. 


\section{RESULTS}

\section{Patient characteristics}

Among 1845 kidney recipients transplanted between January 1, 2008 and December 31, 2012, we identified 504 (27.3\%) patients with post-transplant anti-AT1R antibodies and 1341 (72.7\%) patients without post-transplant anti-AT1R antibodies. Table $\mathbf{1}$ shows the demographic and clinical characteristics of the patients at the time of allograft evaluation according to the presence of post-transplant anti-AT1R antibodies. Compared with patients without post-transplant anti-AT1R antibodies, patients with post-transplant anti-AT1R antibodies were significantly younger (49.3 (12.6) vs. 46.9 (14.5) years old; $p=0.001)$, more often women ( $n=497 / 1341$ (37.1\%) vs. $n=247 / 504$ (49.0\%); $p<0.001)$, had a higher prevalence of previous kidney transplantation ( $n=216 / 1341$ (16.1\%) vs. $n=118 / 504(23.4 \%) ; p<0.001)$, and showed a higher level of sensitization against HLA antigens at the time of transplantation, with a mean calculated panel of reactive HLA antibodies of 38.3 (34.2) vs. $45.2(36.3) \%(p<0.001)$.

\section{Kidney allograft survival}

The median follow-up after antibody screening was 7.23 years (interquartile range, 4.13-9.03).

Figure 1A shows kidney allograft survival according to anti-AT1R antibody status after transplantation. Patients with post-transplant anti-AT1R antibodies had decreased kidney allograft survival compared with patients without post-transplant anti-AT1R antibodies (7-year allograft survival after antibody screening of $76.4 \%$; $95 \% \mathrm{Cl}, 72.1-80.1$ vs. $84.8 \%$; $95 \% \mathrm{Cl}, 82.6$ 86.7; $\mathrm{p}<0.001)$. Higher levels of circulating anti-AT1R antibodies were associated with increasing incidence of allograft loss (Figure S1). Patients with anti-AT1R antibodies and antiHLA DSAs had the worst allograft survival after antibody screening $(60.2 \% ; 95 \% \mathrm{Cl}, 50.4-68.7)$ compared with patients with only anti-HLA DSAs $(75.3 \%$; $95 \% \mathrm{CI}, 69.9-79.8)$, those with only 
anti-AT1R antibodies $(81.9 \%, 95 \% \mathrm{Cl} ; 77.3-85.7)$ and those without these antibodies $(87.9 \%$; 95\% Cl, 85.6-89.9, $\mathrm{p}<0.001$ ) (Figure 1B).

The univariate associations of clinical, histological and immunological factors with kidney allograft loss are shown in Table 2. In multivariable analysis, the following independent determinants of kidney allograft loss were identified: glomerular filtration rate (HR, 0.21 ; 95\% $\mathrm{Cl}, 0.16-0.29 ; \mathrm{p}<0.001)$, proteinuria $(\mathrm{HR}, 2.25 ; 95 \% \mathrm{Cl}, 1.85-2.73 ; \mathrm{p}<0.001)$, anti-HLA DSA and anti-AT1R antibody status (HR, 1.49; 95\%Cl, 1.07-2.06 for anti-AT1R antibodies alone; $\mathrm{HR}, 1.38 ; 95 \% \mathrm{Cl}, 1.05-1.84$ for anti-HLA DSAs alone and $\mathrm{HR}, 2.26$; 95\% $\mathrm{Cl}, 1.52-3.36$ for both antibodies $(p<0.001))$, glomerulitis and peritubular capillaritis $(H R, 1.79 ; 95 \% C l, 1.32-2.43$; $\mathrm{p}<0.001)$ and interstitial fibrosis and tubular atrophy $(\mathrm{HR}, 1.29 ; 95 \% \mathrm{Cl}, 1.00-1.67 ; \mathrm{p}=0.046)$ (Table 3).

\section{Kidney allograft injury}

Kidney allograft injury according to anti-AT1R antibody status

Patients with anti-AT1R antibodies showed a higher incidence of histological features of active antibody-mediated rejection at one year after transplantation as defined by the international classification for allograft rejection ${ }^{34}$ (microvascular inflammation with sum of glomerulitis and peritubular capillaritis Banff scores $>1$ ) compared with patients without anti-AT1R antibodies: 126/504 (25.0\%) vs. 173/1341 (12.9\%); p<0.001. Patients with anti-AT1R antibodies had a greater incidence of vascular rejection lesions, including microcirculation inflammation (incidence of glomerulitis of 147/504 (29.2\%) vs. 277/1341 (20.7\%); $\mathrm{p}<0.001$ and incidence of peritubular capillaritis of $145 / 504(28.8 \%)$ vs. $232 / 1341 \quad(17.3 \%) ; p<0.001)$ and arterial inflammation (incidence of intimal arteritis of 56/504 (11.1\%) vs. 53/1341 (4.0\%); $p<0.001$ ), compared with patients without anti-AT1R antibodies (Table 4). Higher levels of circulating anti-AT1R antibodies were associated with increased risk of glomerulitis, peritubular capillaritis and intimal arteritis (Figure 2). Stratified analysis according to the type of allograft biopsy showed the consistency of these associations in patients undergoing clinical indication biopsy within the first year after transplantation and in patients undergoing protocol biopsy one year after transplantation (Table S1). 


\section{Stratified analysis according to anti-HLA DSA status}

Stratified analysis according to anti-HLA DSA status revealed the consistency of the associations between anti-AT1R antibodies and allograft injury in patients without anti-HLA DSAs and in those with anti-HLA DSAs (Table S2). The incidence of histological features of active antibody-mediated rejection at one year after transplantation was increased in patients with anti-AT1R antibodies compared with patients without anti-AT1R antibodies among patients without anti-HLA DSAs ( $n=51 / 371,13.7 \%$ vs. $n=26 / 1007,2.6 \% ; p<0.001)$ as well as in patients with anti-HLA DSAs ( $n=75 / 133,56.4 \%$ vs. $n=147 / 334,44.0 \% ; p=0.016)$. In patients without anti-HLA DSAs $(n=1378)$, those with anti-AT1R antibodies $(n=371)$ showed greater incidence of microvascular (incidence of glomerulitis of 68/371 (18.3\%) vs. 114/1007 (11.3\%); $p=0.001$ and incidence of peritubular capillaritis of $64 / 371$ (17.3\%) vs. $73 / 1007$ (7.3\%); $\mathrm{p}<0.001$ ) and arterial inflammation (incidence of intimal arteritis of $40 / 371(10.8 \%$ ) vs. $34 / 1007$ (3.4\%); $p<0.001)$, compared with patients without anti-AT1R antibodies $(n=1007)$. Among patients with anti-HLA DSAs $(n=467)$, those with anti-AT1R antibodies $(n=133)$ showed greater incidence of microvascular (incidence of glomerulitis of 79/133 (59.4\%) vs. 163/334 (48.8\%); $p=0.039$ and incidence of peritubular capillaritis of $81 / 133(60.9 \%)$ vs. $159 / 334$ (47.6\%); $p=0.009$ ) and arterial inflammation (incidence of intimal arteritis of 16/133 (12.0\%) vs. 19/334 (5.7\%); $p=0.019)$, compared with patients without anti-AT1R antibodies $(n=334)$.

\section{Anti-angiotensin II type 1 receptor antibody-associated rejection phenotype}

Among 299 (16.2\%) patients with histological features of active antibody-mediated rejection (microvascular inflammation with sum of glomerulitis and peritubular capillaritis Banff scores >1) (Table 5), the detection of anti-AT1R antibodies identified $51 / 77$ (66.2\%) patients as having active antibody-mediated rejection in patients without anti-HLA DSAs. Among them, 36 (70.6\%) patients had pre-existing anti-AT1R antibodies detected in the sera collected at the time of transplantation and $15(29.4 \%)$ patients were found to have de novo anti-AT1R antibodies. Patients with pre-existing anti-AT1R antibodies $(n=36)$ showed increased levels of 
anti-AT1R antibodies between the time of transplantation and the time of ABMR diagnosis $(p<0.001$, Figure S2)

Compared with patients with prototypical anti-HLA DSA-mediated rejection (HLA-DSA+, AT1R-Ab-, $n=147$ ), patients with anti-AT1R antibody-associated rejection (HLA-DSA-, AT1RAb+, $n=51)$ exhibited greater prevalence of hypertension $(n=46 / 147(31.3 \%)$ vs. $n=32 / 51$ (62.7\%); $p<0.001)$, similar glomerular filtration rate $(32.5(20.7)$ vs. $34.2(18.9) \mathrm{mL} / \mathrm{min} / 1.73$ $\left.\mathrm{m}^{2} ; \mathrm{p}=0.61\right)$ and proteinuria level $(1.08(1.60)$ vs. $0.93(1.57) ; \mathrm{p}=0.56)$, and similar cold ischemia time (18.3 (9.5) vs. $17.4(10.4) ; p=0.57)$. Antibody-mediated rejection was diagnosed at a median time since transplantation of 11.3 months (IQR, $2.8-12.0)$ in patients with antiAT1R antibody-associated rejection vs. 5.6 months (IQR, 2.8 - 11.3) in patients with anti-HLA DSA-mediated rejection $(p=0.11)$. Patients with anti-AT1R antibody-associated rejection showed greater prevalence of arterial inflammation ( $n=18 / 147(12.2 \%)$ vs. $n=22 / 51(43.1 \%)$; $p<0.001)$, decreased prevalence of complement deposition in peritubular capillaries $(n=73 / 147$ $(49.7 \%)$ vs. $n=7 / 51 \quad(13.7 \%) ; p<0.001)$ and increased endothelial activation in allografts reflected by higher levels of expression of ENDATs $(p=0.013)$ compared to patients with prototypical anti-HLA DSA-mediated rejection. Figure 3 illustrates the pattern of complementindependent antibody-mediated vascular rejection observed in kidney allografts of patients with circulating anti-AT1R antibodies. 


\section{DISCUSSION}

In a prospective cohort of 1845 kidney transplant recipients, we observed that the presence of circulating non-HLA agonistic anti-AT1R antibodies was associated with increased incidence of antibody-mediated allograft rejection at one year after transplantation and decreased longterm allograft survival. These increased risks of allograft rejection and allograft loss associated with anti-AT1R antibodies were present in patients without anti-HLA DSAs and in those with anti-HLA DSAs, with both a main effect and a synergistic effect of these antibodies on allograft injury. Anti-AT1R antibody-associated rejection was characterized by hypertension, active vascular lesions (microcirculation inflammation and arterial inflammation), increased expression of ENDATs, which revealed antibody interaction with the vascular endothelium, ${ }^{34}$ and low levels of complement deposition in allograft capillaries. The detection of anti-AT1R antibodies identified $51(66.2 \%)$ patients as having antibody-mediated rejection among 77 patients with histological features of antibody-mediated rejection, in whom a definitive diagnosis could not be reached due to the lack of serological evidence of anti-HLA DSAs.

The broadest evidence suggesting a role of non-HLA immunity in transplantation was provided by a large registry study that observed a significant association between the presence of lymphocytotoxic antibodies detected before transplantation and allograft survival in kidney recipients from HLA-identical sibling donors, although the nature of these antibodies and their pathogenic expression in allografts were not evaluated. ${ }^{38}$ Description of antibody-mediated AT1R activation in vascular cells and proof of concept in animal model emphasized the vasculature as the critical interface between the recipient immune system and the transplanted organ even in the absence of classical complement activation features. ${ }^{10}$ Several studies have evaluated the potential role of agonistic antibodies that target AT1R and have reported 
conflicting results. These studies were limited by small sample size, the inclusion of selected populations, the lack of systematic allograft biopsy performance for assessing correlations between immunological status and injury phenotype, and/or the lack of evaluation of concomitant anti-HLA DSA status using a sensitive technique. ${ }^{10-22,24,26-31}$ Therefore, no definitive conclusion has been reached regarding the clinical value of anti-AT1R antibody screening as part of the immunological assessment of transplant recipients, which, to date, remains entirely based on the HLA system. ${ }^{7,33}$

Our data support that post-transplant non-HLA agonistic anti-AT1R antibodies may contribute to a specific type of kidney allograft rejection characterized by vascular injury with microvascular and arterial inflammation, endothelial activation and lack of complement activation. These findings are consistent with previous reports of kidney transplant recipients with anti-AT1R antibody-associated allograft injury who often demonstrated involvement of allograft arteries and lack of complement deposition. ${ }^{10}$ Moreover, we observed a biological gradient between the level of circulating anti-AT1R antibodies and allograft antibody-mediated injury and allograft loss, with exposure to higher levels of anti-AT1R antibodies being associated with greater prevalence of concomitant microcirculation and arterial injuries and greater incidence of allograft loss, reinforcing the potential causal role of these antibodies as mediators of allograft rejection. Biological plausibility is supported by the current knowledge regarding the direct endothelial pathogenicity of agonistic anti-AT1R antibodies attributed to AT1R activation process in different disease contexts ranging from allograft rejection with vascular involvement to severe systemic autoimmune vasculopathies. ${ }^{39-41}$

One of the major limitations faced by current diagnostic standards in organ transplantation is represented by the diagnostic uncertainty in patients showing histological features of antibodymediated rejection without evidence for donor-specific anti-HLA antibodies, with discordances between clinicians' diagnosis and reference standard in nearly $50 \%$ of cases. ${ }^{42}$ This diagnostic uncertainty leads to unresolved therapeutic questions because current approaches in patients with antibody-mediated rejection are directed towards removal of circulating anti-HLA DSAs, 
blockade of their effects and reduction of their production. ${ }^{43}$ The identification of anti-AT1R antibodies as a potential mediator of allograft rejection and loss, independent of the presence of anti-HLA DSAs, has important implications for the clinical management of transplant recipients by enabling the development of specific therapeutic strategies. Future studies should evaluate the efficacy of current antibody-targeting therapies, such as plasma exchange and intravenous immune globulins, which are the standard of care treatment for anti-HLA antibody-mediated allograft rejection. ${ }^{43}$ Moreover, our study paves the way for future therapeutical approaches; a selective blockade of AT1Rs using sartans could alleviate allograft vascular injury and prevent long-term allograft loss mediated by agonistic anti-AT1R antibodies. Reports have actually indicated good outcomes using AT1R blockers for treating kidney transplant recipients with anti-AT1R antibody-associated rejection in terms of clinical and histological course ${ }^{44}$ and allograft survival ${ }^{10}$, as well as for preventing kidney allograft rejection in recipients with high levels of circulating anti-AT1R antibodies. ${ }^{45}$ However, no clinical trial has been conducted to date to demonstrate the benefit of such approaches. In addition, AT1R blockers may exert a clinically relevant immunomodulatory effect exemplified by a reduction in IFN-y generation by T cells as demonstrated in vitro and in vivo. ${ }^{46}$ Finally, the low level of complement activation observed in patients with anti-AT1R antibody-mediated rejection suggests that strategies based on complement inhibition, such as terminal C5 or proximal $\mathrm{C} 1$ component blockade that have been used in patients with anti-HLA DSAs ${ }^{47}$ may not be relevant in patients with anti-AT1R antibody-mediated rejection. Potential therapeutic advances in anti-AT1R antibody-mediated vascular rejection may offer new opportunities for the management of systemic autoimmune vasculopathies related to AT1R activation.

Our study has some limitations. The assessment of anti-AT1R antibody status and allograft injury was limited to the first year after transplantation to limit the confounding background of previous allograft injuries. One has to consider potential inter-laboratory variability of antiAT1R antibody measurement, which remains to be investigated, although most studies have reported a comparable cut-point for anti-AT1R antibody positivity. Additionally, there might be residual confounding in the association between anti-AT1R antibodies and allograft survival 
and injury represented by other non-HLA antibodies. Finally, although our data indicate a clinical value of anti-AT1R antibody assessment in patients with pathological features of antibody-mediated rejection (with or without detectable anti-HLA DSAs), specific studies dedicated to the evaluation of cost-effectiveness, including the consideration of resourcelimited settings and the cost related to allograft biopsies triggered by anti-AT1R antibody positivity, are needed to substantiate the utility of a systematic monitoring of anti-AT1R antibodies as part of the standard of care management of kidney transplant recipients. Nevertheless, given the strong phenotypic association with C4d negative ABMR one should consider anti-AT1R antibodies as an important diagnostic tool.

In conclusion, our study showed the clinical relevance of the screening for circulating functional non-HLA anti-AT1R antibodies in addition to the current approach for immunological assessment of kidney transplant recipients by identifying patients at high risk of allograft rejection and allograft loss independent of the HLA system. We completed the current understanding of autoimmune endothelial injury related to anti-AT1R autoantibodies, including systemic vascular disorders such as pre-eclampsia and scleroderma, by identifying a new pattern of allograft vascular rejection associated with anti-AT1R antibodies in kidney transplant recipients. Recognition of complementindependent anti-AT1R antibody-mediated vascular rejection could lead to the development of new treatment strategies targeting circulating antibodies and AT1Rs to improve allograft survival, in particular in forms of allograft rejection without evidence for HLA antibody involvement, for which no therapeutic strategy has been defined. The clinical relevance of anti-AT1R antibodies might be extended beyond renal transplantation to heart transplantation and other solid organs. 


\section{METHODS}

\section{Participants and study design}

We prospectively enrolled all consecutive patients who underwent $A B O$ blood group compatible kidney transplantation in Necker Hospital and Saint-Louis Hospital (Paris, France) between January 1, 2008, and December 31, $2012 \quad(n=1957)$ (ClinicalTrials.gov, NCT03466775). These kidney recipients underwent allograft evaluation including assessment of allograft function, circulating anti-HLA DSAs and anti-AT1R antibodies, and histological parameters measured on allograft biopsy within the first year after transplantation. Allograft evaluation was performed at the time of the first episode of biopsy-proven allograft rejection occurring in the first year after transplantation or by protocol at one year after transplantation in patients without any rejection episodes diagnosed in the first year after transplantation. We excluded patients receiving multi-organ transplantation $(n=19)$, patients without allograft biopsy performed within the first year after transplantation $(n=56)$, patients with inadequate allograft biopsy according to the Banff classification for allograft rejection ${ }^{48}(n=21)$, patients without available serum for the assessment of anti-AT1R antibodies $(n=10)$ or anti-HLA DSAs $(n=6)$. Patients were followed annually up until December 31, 2017.

The transplantation allocation system followed the rules of the French national agency for organ procurement (Agence de la Biomédecine). All transplants were performed with negative standard National Institutes of Health and anti-human globulin T and B cell cytotoxicity crossmatches on serum obtained at the time of transplantation. All patients provided written informed consent.

\section{Clinical data}

The clinical data on donors and recipients were extracted from the DIVAT database: 
(www.divat.fr). Coding was used to ensure strict donor and recipient anonymity. The data were entered into the database in real time or at each transplant anniversary. This database is approved by the National French Commission for Bioinformatics Data and Patient Liberty (Commission Nationale de l'Informatique et des Libertés registration no. 1016618; validated June 8,2004$)$. The data were retrieved from the database on December 31, 2017. Renal function was assessed by the estimated glomerular filtration rate with the abbreviated Modification of Diet in Renal Disease formula. ${ }^{49}$ Hypertension was defined by a systolic blood pressure $\geq 140 \mathrm{mmHg}$ and/or a diastolic blood pressure $\geq 90 \mathrm{mmHg}$.

\section{Detection of anti-angiotensin II type 1 antibodies and donor-specific anti-HLA antibodies}

All patients were tested for the presence of circulating anti-AT1R antibodies using a quantitative ELISA (Celltrend, Luckenwalde, Germany). A value of $10 \mathrm{U} / \mathrm{mL}$ was considered the cut-off point for anti-AT1R antibody positivity after examining prior studies of its association with allograft rejection and loss; ${ }^{12,14-17,20-22,24,28,31}$ this cut-off point also represented the third quartile value in the distribution of anti-AT1R antibody values in the entire study population (Figure S3).

The presence of circulating anti-HLA-A, -B, -Cw, -DR, -DQ, and -DP DSAs was assessed using single-antigen flow bead assays (One Lambda, Inc., Canoga Park, CA, USA) that were used on a Luminex platform (Regional Histocompatibility Laboratory, Paris, France). All beads showing a normalized mean fluorescence intensity (MFI) $>1000$ were considered positive. HLA typing of all the kidney transplant donors and recipients was performed by molecular biology (Innolipa HLA Typing Kit, Innogenetics, Gent, Belgium).

\section{Histological and immunochemical phenotyping of kidney allograft biopsies}

All allograft biopsy specimens (304 allograft biopsies performed for clinical indication, with a median time between transplantation and allograft biopsy of 3.8 months (interquartile range, 2.37.3), and 1541 protocol biopsies performed at one year after transplantation) were scored and graded from 0 to 3 according to the updated Banff criteria ${ }^{34}$ by a trained pathologist. The 
pathologist examined the following histological factors: glomerulitis, peritubular capillaritis, mononuclear cell interstitial inflammation, tubulitis, intimal arteritis, chronic allograft glomerulopathy, interstitial fibrosis and tubular atrophy, arteriolar hyaline thickening, and vascular fibrous intimal thickening. The pathologist was blinded to the clinical data and to the original pathological report. Complement split-product C4d staining was performed by immunochemical analysis on paraffin sections using polyclonal rabbit anti-human C4d antibodies (Biomedica Gruppe, Vienna, Austria).

Allograft diagnoses were defined according to the Banff classification. Active ABMR was defined by i) histologic evidence of acute tissue injury, including 1 or more of the following: glomerulitis score $>0$ and/or peritubular capillaritis score $>0$ (in the absence of recurrent or de novo glomerulonephritis and with glomerulitis score $\geq 1$ in case of acute $\mathrm{T}$ cell-mediated rejection, borderline infiltrate, or infection), intimal arteritis score $>0$, acute thrombotic microangiopathy in the absence of any other cause, acute tubular injury in the absence of any other apparent cause; ii) evidence of current/recent antibody interaction with vascular endothelium, including 1 or more of the following: C4d score $>0$, glomerulitis + peritubular capillaritis scores $\geq 2$; and iii) serologic evidence of anti-HLA DSAs and/or anti-AT1R antibodies.

\section{RNA extraction and gene expression analysis in kidney allograft biopsies}

Kidney allograft biopsies showing pathological features of active antibody-mediated rejection, as defined by the Banff classification for allograft rejection (microcirculation inflammation with sum of glomerulitis and peritubular capillaritis Banff scores $>1)^{34}$ were processed for microarray analysis as previously described. ${ }^{50}$ One biopsy sample was immediately placed in a dry tube and stored at $80^{\circ} \mathrm{C}$. RNA extraction, labelling and hybridization to HG-U219 GeneChip arrays (Affymetrix, Santa Clara, CA, USA) were performed according to the manufacturer's protocols (www.affymetrix.com). The microarrays were scanned using the Gene Array Scanner (Affymetrix) and processed with GeneChip Operating Software Version 1.4.0 (Affymetrix), and robust multiarray averaging was used to normalize the microarrays. The microarray data files were processed using robust multiarray analysis in Bioconductor. 
We measured and compared intra-graft expression levels of ENDATs according to anti-AT1R antibodies and anti-HLA DSA status. ENDATs represent a pathogenesis-based transcript set that reflects endothelial activation. ${ }^{51}$ The details of the probe set can be found in Table S3.

\section{Outcomes}

The primary outcomes were kidney allograft loss and the incidence of biopsy-proven allograft rejection at one year post-transplantation. Kidney allograft loss was defined as the patient's return to chronic dialysis or preemptive subsequent kidney transplant. Allograft rejection episodes were diagnosed according to the Banff classification for allograft rejection. ${ }^{34}$ Secondary outcomes included allograft injury phenotype based on histological allograft elementary lesions defined by the Banff classification and ENDAT expression measured in kidney allograft biopsies showing histological features of active antibody-mediated rejection (sum of glomerulitis and peritubular capillaritis Banff scores $>1$ ).

\section{Statistical analysis}

Continuous variables were described using means with standard deviations (SDs) unless otherwise stated. We compared means and proportions using Student's t-test and chi-square test, respectively (or Mann-Whitney U test and Fisher's exact test, respectively, if appropriate). Survival was analyzed from the time of post-transplant allograft biopsy to a maximum of seven years after allograft evaluation, with kidney allograft loss as the event of interest. In case of death with a functioning allograft, allograft survival was censored at time of death. Rates of kidney allograft survival were plotted on Kaplan-Meier curves and compared according to anti-AT1R antibodies and anti-HLA DSA status with the use of the log-rank test. Cox proportional hazards models were used to quantify hazard ratios $(\mathrm{HR})$ and $95 \%$ confidence intervals $(\mathrm{Cl})$ for time to kidney allograft loss. The association of clinical, histological, and immunological parameters evaluated at the time of allograft evaluation with allograft loss were assessed in separate univariate and multivariable Cox regression analyses. The best transformation for continuous variables was determined using 
fractional polynomial method. A p-value threshold of 0.20 for entering variables into the multivariable model was used. The factors identified in these analyses were thereafter included in a final multivariable model with stepwise backward elimination. The proportional hazards assumption of the Cox model was verified with the log-graphic method.

We used penalized splines to represent the relationship between anti-AT1R antibody levels and the odds ratio for the presence of glomerulitis, peritubular capillaritis and intimal arteritis and the HR for the occurrence of allograft loss. Biologic plausibility (that is, monotonicity) was considered, along with Akaike's information criterion, in selecting the optimal degrees of freedom. ${ }^{52}$

All tests were two-sided, and except in the univariate analyses, all p-values $<0.05$ were regarded as statistically significant. All of the statistical analyses were performed using $R$ version 3.4 .3 (R Development Core Team, Vienna, Austria).

\section{Contributors}

C Lefaucheur, AL and DD conceived and designed the study. C Lefaucheur, DV, YB, DP, AL and DD drafted the manuscript. C Lefaucheur, DV, YB, AP, OA, JPDVH, JLT, PH, AL, DG, C Legendre and DD analyzed and interpreted the data. AP prepared the serum samples. JPDVH reported pathology results. All authors were involved in revising the article and approved the final version of the manuscript. All the authors had full access to the data and made the decision collectively to submit the manuscript for publication.

\section{Funding source}

The cost of clinical and microarray experiments and the effort of all the co-authors involved in data management and analysis, and manuscript preparation were paid through a grant from the French National Institute of Health and Medical Research (ATIP-AVENIR 6068KS-RSE16068KSA). The funder had no role in study design, data collection and analysis, decision to publish, or preparation of the manuscript.

\section{Study approval}

This study was approved by Institutional Review Boards of Necker and Saint-Louis Hospitals. The 
DIVAT database network has been approved by the National French Commission for bioinformatics data and patient liberty: CNIL, registration number: 1016618, validated 8th June 2004.

\section{Conflict of interests}

The authors declare that they had no financial relationships with any organizations that might have an interest in the submitted work in the past three years and no other relationships or activities that could appear to have influenced the submitted work.

\section{Supplementary Material}

Supplementary Table 1. Kidney allograft injury at the time of antibody screening according to the presence of circulating anti-angiotensin II type 1 receptor antibodies and stratified on the basis of allograft biopsy indication.

Supplementary Table 2. Kidney allograft injury at the time of antibody screening according to the presence of circulating anti-angiotensin II type 1 receptor antibodies and stratified on the basis of donor-specific anti-HLA antibody status.

Supplementary Table 3. Endothelial-associated transcript (ENDAT) gene list with their corresponding probe set.

Supplementary Figure 1. Risk of kidney allograft loss according to post-transplant circulating anti-angiotensin II type 1 receptor antibody level.

Supplementary Figure 2. Distribution of pre-transplant and post-transplant circulating antiangiotensin II type 1 receptor antibody levels in patients with pre-existing anti-AT1R antibodyassociated rejection without anti-HLA DSAs.

Supplementary Figure 3. Distribution of post-transplant circulating anti-angiotensin II type 1 receptor antibody levels.

Supplementary Methods. Induction and maintenance immunosuppressive therapy protocols. 
Supplementary information is available at Kidney International's website.

\section{REFERENCES}

1. Lefaucheur C, Loupy A, Vernerey D, et al. Antibody-mediated vascular rejection of kidney allografts: a population-based study. Lancet. 2013,381:313-319

2. Colvin MM, Cook JL, Chang P, et al. Antibody-mediated rejection in cardiac transplantation: emerging knowledge in diagnosis and management: a scientific statement from the American Heart Association. Circulation. 2015;131:1608-1639

3. DeNicola MM, Weigt SS, Belperio JA, et al. Pathologic findings in lung allografts with antiHLA antibodies. J Heart Lung Transplant. 2013;32:326-332

4. Thurairajah $\mathrm{PH}$, Carbone $\mathrm{M}$, Bridgestock $\mathrm{H}$, et al. Late acute liver allograft rejection; a study of its natural history and graft survival in the current era. Transplantation. 2013,95:955-959

5. Nankivell BJ, Alexander SI. Rejection of the kidney allograft. N Engl J Med. 2010;363:14511462

6. Valenzuela NM, Reed EF. Antibody-mediated rejection across solid organ transplants: manifestations, mechanisms, and therapies. J Clin Invest. 2017;127:2492-2504

7. Tait BD, Susal C, Gebel HM, et al. Consensus guidelines on the testing and clinical management issues associated with HLA and non-HLA antibodies in transplantation. Transplantation. 2013;95:19-47

8. Jackson AM, Sigdel TK, Delville M, et al. Endothelial cell antibodies associated with novel targets and increased rejection. J Am Soc Nephrol. 2015;26:1161-1171

9. Grafft CA, Cornell LD, Gloor JM, et al. Antibody-mediated rejection following transplantation from an HLA-identical sibling. Nephrol Dial Transplant. 2010;25:307-310 
10. Dragun D, Muller DN, Brasen JH, et al. Angiotensin II type 1-receptor activating antibodies in renal-allograft rejection. N Engl J Med. 2005;352:558-569

11. Reinsmoen NL, Lai $\mathrm{CH}$, Heidecke $\mathrm{H}$, et al. Anti-angiotensin type 1 receptor antibodies associated with antibody mediated rejection in donor HLA antibody negative patients. Transplantation. 2010;90:1473-1477

12. Fuss A, Hope CM, Deayton S, et al. C4d-negative antibody-mediated rejection with high anti-angiotensin II type I receptor antibodies in absence of donor-specific antibodies. Nephrology (Carlton). 2015;20:467-473

13. Taniguchi M, Rebellato LM, Cai J, et al. Higher risk of kidney graft failure in the presence of anti-angiotensin II type-1 receptor antibodies. Am J Transplant. 2013;13:2577-2589

14. Giral M, Foucher Y, Dufay A, et al. Pretransplant sensitization against angiotensin II type 1 receptor is a risk factor for acute rejection and graft loss. Am J Transplant. 2013;13:25672576

15. In JW, Park H, Rho EY, et al. Anti-angiotensin type 1 receptor antibodies associated with antibody-mediated rejection in patients without preformed HLA-donor-specific antibody. Transplant Proc. 2014;46:3371-3374

16. Banasik M, Boratynska M, Koscielska-Kasprzak K, et al. Non-HLA antibodies: angiotensin II type 1 receptor (anti-AT1R) and endothelin-1 type A receptor (anti-ETAR) are associated with renal allograft injury and graft loss. Transplant Proc. 2014;46:2618-2621

17. Lee J, Huh KH, Park Y, et al. The clinicopathological relevance of pretransplant antiangiotensin II type 1 receptor antibodies in renal transplantation. Nephrol Dial Transplant. $2017,32: 1244-1250$

18. Pearl MH, Zhang Q, Palma Diaz MF, et al. Angiotensin II Type 1 receptor antibodies are associated with inflammatory cytokines and poor clinical outcomes in pediatric kidney transplantation. Kidney Int. 2018;93:260-269

19. Philogene MC, Zhou S, Lonze BE, et al. Pre-transplant Screening for Non-HLA Antibodies: Who should be Tested? Hum Immunol. 2018; 
20. Fichtner A, Susal C, Schroder C, et al. Association of angiotensin II type 1 receptor antibodies with graft histology, function and survival in paediatric renal transplant recipients. Nephrol Dial Transplant. 2018;

21. Malheiro J, Tafulo S, Dias L, et al. Deleterious Effect of Anti-Angiotensin II Type 1 Receptor Antibodies Detected Pretransplant on Kidney Graft Outcomes is Both Proper and Synergistic WITH DONOR-SPECIFIC ANTI-HLA ANTIBODIES. Nephrology (Carlton). 2018;

22. Philogene MC, Bagnasco S, Kraus ES, et al. Anti-Angiotensin II Type 1 Receptor and AntiEndothelial Cell Antibodies: A Cross-Sectional Analysis of Pathological Findings in Allograft Biopsies. Transplantation. 2017;101:608-615

23. Lee J, Park Y, Kim BS, et al. Clinical implications of angiotensin II type 1 receptor antibodies in antibody-mediated rejection without detectable donor-specific HLA antibodies after renal transplantation. Transplant Proc. 2015;47:649-652

24. Hiemann NE, Meyer R, Wellnhofer E, et al. Non-HLA antibodies targeting vascular receptors enhance alloimmune response and microvasculopathy after heart transplantation. Transplantation. 2012;94:919-924

25. Reinsmoen NL, Mirocha J, Ensor CR, et al. A 3-Center Study Reveals New Insights Into the Impact of Non-HLA Antibodies on Lung Transplantation Outcome. Transplantation. $2017 ; 101: 1215-1221$

26. O'Leary JG, Demetris AJ, Philippe A, et al. Non-HLA Antibodies Impact on C4d Staining, Stellate Cell Activation and Fibrosis in Liver Allografts. Transplantation. 2017;101:23992409

27. Hesemann LE, Subramanian V, Mohanakumar T, et al. De novo development of antibodies to kidney-associated self-antigens angiotensin II receptor type I, collagen IV, and fibronectin occurs at early time points after kidney transplantation in children. Pediatr Transplant. 2015;19:499-503

28. Reinsmoen NL, Lai CH, Mirocha J, et al. Increased negative impact of donor HLA-specific together with non-HLA-specific antibodies on graft outcome. Transplantation. 2014;97:595601 
29. Urban M, Slavcev A, Gazdic T, et al. The impact of angiotensin II type 1 receptor antibodies on post-heart transplantation outcome in Heart Mate II bridged recipients. Interact Cardiovasc Thorac Surg. 2016;22:292-297

30. Pinelli DF, Friedewald JJ, Haarberg KMK, et al. Assessing the potential of angiotensin II type 1 receptor and donor specific anti-endothelial cell antibodies to predict long-term kidney graft outcome. Hum Immunol. 2017;78:421-427

31. Deltombe C, Gillaizeau F, Anglicheau D, et al. Is pre-transplant sensitization against angiotensin II type 1 receptor still a risk factor of graft and patient outcome in kidney transplantation in the anti-HLA Luminex era? A retrospective study. Transpl Int. 2017,30:1150-1160

32. Costanzo MR, Dipchand A, Starling R, et al. The International Society of Heart and Lung Transplantation Guidelines for the care of heart transplant recipients. J Heart Lung Transplant. 2010;29:914-956

33. Kobashigawa J, Colvin M, Potena L, et al. The management of antibodies in heart transplantation: An ISHLT consensus document. J Heart Lung Transplant. 2018;

34. Loupy A, Haas M, Solez K, et al. The Banff 2015 Kidney Meeting Report: Current Challenges in Rejection Classification and Prospects for Adopting Molecular Pathology. Am J Transplant. 2017;17:28-41

35. Berry GJ, Burke MM, Andersen C, et al. The 2013 International Society for Heart and Lung Transplantation Working Formulation for the standardization of nomenclature in the pathologic diagnosis of antibody-mediated rejection in heart transplantation. J Heart Lung Transplant. 2013;32:1147-1162

36. Demetris AJ, Bellamy C, Hubscher SG, et al. 2016 Comprehensive Update of the Banff Working Group on Liver Allograft Pathology: Introduction of Antibody-Mediated Rejection. Am J Transplant. 2016;16:2816-2835

37. Levine DJ, Glanville AR, Aboyoun C, et al. Antibody-mediated rejection of the lung: A consensus report of the International Society for Heart and Lung Transplantation. $J$ Heart Lung Transplant. 2016;35:397-406 
38. Opelz G, Collaborative Transplant S. Non-HLA transplantation immunity revealed by lymphocytotoxic antibodies. Lancet. 2005;365:1570-1576

39. Dragun D, Catar R, Philippe A. Non-HLA antibodies against endothelial targets bridging allo- and autoimmunity. Kidney Int. 2016,90:280-288

40. Thway TM, Shlykov SG, Day MC, et al. Antibodies from preeclamptic patients stimulate increased intracellular $\mathrm{Ca} 2+$ mobilization through angiotensin receptor activation. Circulation. 2004;110:1612-1619

41. Riemekasten G, Philippe A, Nather M, et al. Involvement of functional autoantibodies against vascular receptors in systemic sclerosis. Ann Rheum Dis. 2011,70:530-536

42. Schinstock CA, Sapir-Pichhadze R, Naesens M, et al. Banff Survey on Antibody Mediated Rejection Clinical Practices in Kidney Transplantation: Diagnostic Misinterpretation has Potential Therapeutic Implications. Am J Transplant. 2018;

43. Archdeacon P, Chan M, Neuland C, et al. Summary of FDA antibody-mediated rejection workshop. Am J Transplant. 2011;11:896-906

44. Guzzo I, Morolli F, Camassei FD, et al. Acute kidney transplant rejection mediated by angiotensin II type 1 receptor antibodies in a pediatric hyperimmune patient. Pediatr Nephrol. 2017;32:185-188

45. Carroll RP, Riceman M, Hope CM, et al. Angiotensin II type-1 receptor antibody (AT1Rab) associated humoral rejection and the effect of peri operative plasma exchange and candesartan. Hum Immunol. 2016;77:1154-1158

46. Weidanz JA, Jacobson LM, Muehrer RJ, et al. ATR blockade reduces IFN-gamma production in lymphocytes in vivo and in vitro. Kidney Int. 2005;67:2134-2142

47. Stegall MD, Diwan T, Raghavaiah S, et al. Terminal complement inhibition decreases antibody-mediated rejection in sensitized renal transplant recipients. Am J Transplant. $2011 ; 11: 2405-2413$

48. Racusen LC, Solez K, Colvin RB, et al. The Banff 97 working classification of renal allograft pathology. Kidney Int. 1999;55:713-723 
49. Levey AS, Bosch JP, Lewis JB, et al. A more accurate method to estimate glomerular filtration rate from serum creatinine: a new prediction equation. Modification of Diet in Renal Disease Study Group. Ann Intern Med. 1999;130:461-470

50. Mueller TF, Einecke G, Reeve J, et al. Microarray analysis of rejection in human kidney transplants using pathogenesis-based transcript sets. Am J Transplant. 2007;7:2712-2722

51. Sis B, Jhangri GS, Bunnag S, et al. Endothelial gene expression in kidney transplants with alloantibody indicates antibody-mediated damage despite lack of C4d staining. Am J Transplant. 2009;9:2312-2323

52. Eisen EA, Agalliu I, Thurston SW, et al. Smoothing in occupational cohort studies: an illustration based on penalised splines. Occup Environ Med. 2004;61:854-860 
Table 1. Demographic and clinical characteristics according to the presence of circulating anti-angiotensin II type 1 receptor antibodies.

\begin{tabular}{|c|c|c|c|c|}
\hline Characteristics & $\begin{array}{c}\text { All } \\
\text { patients } \\
(\mathrm{n}=1845)\end{array}$ & $\begin{array}{l}\text { AT1R-Ab } \\
\text { negative } \\
(n=1341)\end{array}$ & $\begin{array}{l}\text { AT1R-Ab } \\
\text { positive } \\
(\mathrm{n}=504)\end{array}$ & $\mathbf{p}$ \\
\hline Recipient age, mean (SD), years & $48.6(13.2)$ & $49.3(12.6)$ & $46.9(14.5)$ & 0.001 \\
\hline Recipient female gender, No. (\%) & $744(40.3)$ & $497(37.1)$ & $247(49.0)$ & $<0.001$ \\
\hline Recipient blood type, №. (\%) & & & & 0.046 \\
\hline$A$ & $852(46.2)$ & $639(47.7)$ & $213(42.3)$ & \\
\hline $\mathrm{B}$ & $162(8.8)$ & $122(9.1)$ & $40(7.9)$ & \\
\hline $\mathrm{O}$ & 754 (40.9) & $531(39.6)$ & $223(44.2)$ & \\
\hline$A B$ & $77(4.1)$ & $49(3.6)$ & $28(5.6)$ & \\
\hline Chronic kidney disease, No. (\%) & & & & 0.160 \\
\hline Glomerulopathy & $481(26.1)$ & $335(25.0)$ & $146(29.0)$ & \\
\hline Vascular nephropathy & $141(7.6)$ & $108(8.1)$ & $33(6.5)$ & \\
\hline Chronic interstitial nephropathy & $224(12.1)$ & $166(12.4)$ & $58(11.5)$ & \\
\hline Congenital nephropathy & 355 (19.3) & $269(20.1)$ & $86(17.1)$ & \\
\hline Diabetes & $167(9.1)$ & $114(8.4)$ & $53(10.5)$ & \\
\hline Other & $76(4.1)$ & $61(4.5)$ & $15(3.0)$ & \\
\hline Not determined & $401(21.7)$ & $288(21.5)$ & $113(22.4)$ & \\
\hline Previous transplantation, No. (\%) & $334(18.1)$ & $216(16.1)$ & $118(23.4)$ & $<0.001$ \\
\hline Preemptive transplantation, №. (\%) & $242(13.1)$ & $176(13.1)$ & $66(13.1)$ & 0.987 \\
\hline Time since dialysis, mean (SD), years & $4.9(4.6)$ & $4.9(4.6)$ & $4.9(4.6)$ & 0.852 \\
\hline Donor age, mean (SD), years & $51.5(16.3)$ & $52.1(16.0)$ & $50.0(17.0)$ & 0.015 \\
\hline Donor male gender, No. (\%) & $1008(54.6)$ & $715(53.3)$ & $293(58.1)$ & 0.064 \\
\hline Donor type, No. (\%) & & & & 0.001 \\
\hline Living & $336(18.2)$ & $220(16.4)$ & $116(23.0)$ & \\
\hline Deceased & $1509(81.8)$ & $1121(83.6)$ & $388(77.0)$ & \\
\hline $\begin{array}{l}\text { Donor serum creatinine, mean (SD), } \\
\mu \mathrm{mol} / \mathrm{L}\end{array}$ & $86.6(51.2)$ & $87.4(54.1)$ & $84.7(42.4)$ & 0.266 \\
\hline Cold ischemia time, mean (SD), hours & $17.7(9.9)$ & $18.0(10.0)$ & $16.8(9.8)$ & 0.017 \\
\hline
\end{tabular}


HLA A mismatch, No. (\%)

0.713

0

1

2

HLA B mismatch, No. (\%)

0

1

2

HLA DR mismatch, No. (\%)

0

1

2

HLA DQ mismatch, No. (\%)

0

1

2

Calculated panel reactive antibody, No. (\%)
$0 \%$
$1-24 \%$
$25-49 \%$
$50-84 \%$
$85-100 \%$

Induction therapy, №. (\%)

Thymoglobuline

Anti-CD25 therapy

None

Maintenance immunosuppression, No.

(\%)

IMDPHi
Tacrolimus
Cyclosporine
mTOR inhibitor
Steroids

Glomerular filtration rate, mean (SD),

$\mathrm{mL} / \mathrm{min} / 1.73 \mathrm{~m}^{2}$

Urine protein/creatinine ratio, mean (SD), $g / g$

Post-transplant HLA DSA, No. (\%)

\section{All HLA DSA}

No. of specificities, mean (SD)

HLA class, No. (\%)

$$
\text { I }
$$$$
\text { II }
$$

$\begin{array}{lll}451(24.5) & 328(24.5) & 123(24.4) \\ 949(51.4) & 696(51.9) & 253(50.2) \\ 445(24.1) & 317(23.6) & 128(25.4)\end{array}$

0.030

$\begin{array}{lll}344(18.6) & 231(17.2) & 113(22.4) \\ 894(48.5) & 667(49.7) & 227(45.1) \\ 607(32.9) & 443(33.1) & 164(32.5)\end{array}$

0.768

$\begin{array}{lll}548(29.7) & 393(29.3) & 155(30.7) \\ 967(52.4) & 704(52.5) & 263(52.2) \\ 330(17.9) & 244(18.2) & 86(17.1)\end{array}$

0.959

$482(26.1) \quad 350(26.1) \quad 132(26.2)$

$1011(54.8) \quad 733(54.7) \quad 278(55.2)$

$352(19.1) \quad 258(19.2) \quad 94(18.6)$

$<0.001$

$\begin{array}{llc}471(25.5) & 393(29.3) & 78(15.5) \\ 289(15.7) & 215(16.0) & 74(14.7) \\ 250(13.5) & 169(12.6) & 81(16.1) \\ 356(19.3) & 241(18.0) & 115(22.8) \\ 479(26.0) & 323(24.1) & 156(30.9)\end{array}$

0.443

$1287(69.8) \quad 925(69.0) \quad 362(71.8)$

$554(30.0) \quad 413(30.8) \quad 141(28.0)$

$4(0.22) \quad 3(0.22) \quad 1(0.20)$

$\begin{array}{cccc}1776(96.3) & 1296(96.6) & 480(95.2) & 0.156 \\ 1267(68.7) & 905(67.5) & 362(71.8) & 0.073 \\ 559(30.3) & 423(31.5) & 136(27.0) & 0.058 \\ 23(1.2) & 16(1.2) & 7(1.4) & 0.814 \\ 1612(87.4) & 1161(86.6) & 451(89.5) & 0.094 \\ 54.8(20.9) & 55.9(21.5) & 51.9(19.0) & <0.001 \\ 0.34(0.78) & 0.28(0.60) & 0.52(1.14) & <0.001 \\ 467(25.3) & 334(24.9) & 133(26.4) & 0.514\end{array}$

$\begin{array}{llll}1.9(1.3) & 1.9(1.2) & 2.0(1.5) & 0.684 \\ & & & 0.817\end{array}$

$96(20.5) \quad 71(21.3) \quad 25(18.7)$

$207(44.2) \quad 146(43.7) \quad 61(45.5)$ 

I+II
165 (35.3)
117 (35.0)
48 (35.8)

\section{Immunodominant HLA DSA*}

HLA class, No. (\%)

I

II

$$
\begin{gathered}
144(30.8) \\
323(69.2) \\
5177 \\
(4434, \\
1103- \\
20746)
\end{gathered}
$$

MFI, mean (SD, range)

\section{HLA DSA detectable before transplantation}

$\begin{array}{cccc}342(18.5) & 233(17.5) & 109(21.4) & 0.053 \\ 3974 & & & \\ (4074, & 3917(4139, & 4096(3936, & \\ 1012- & 1012- & 1158- & 0.669 \\ 12323) & 12323) & 11827) & \end{array}$

Desensitization therapy, No. (\%) $136(7.4)$

$89(6.6)$

47 (9.3)

0.049

Ab, antibody; AT1R, angiotensin II type 1 receptor; DSA, donor-specific antibody; HLA, human leukocyte antigen; IMPDHi, inosine-5'-monophosphate dehydrogenase inhibitor; MFI, mean fluorescence intensity; mTOR, mammalian target of rapamycin; SD, standard deviation

*The highest mean fluorescence intensity value toward a donor-specific allele was considered to be the immunodominant DSA 
Table 2. Determinants of kidney allograft loss assessed at the time of antibody screening: Univariate analysis.

\begin{tabular}{|c|c|c|c|c|c|}
\hline & $\begin{array}{c}\text { Number } \\
\text { of } \\
\text { patients }\end{array}$ & $\begin{array}{c}\text { Number } \\
\text { of } \\
\text { events }\end{array}$ & HR & $95 \% \mathrm{Cl}$ & $\mathbf{p}$ \\
\hline \multicolumn{6}{|l|}{ Clinical } \\
\hline Recipient age, per 1-year increment & 1845 & 285 & 0.99 & $0.98-1.00$ & 0.117 \\
\hline \multicolumn{6}{|l|}{ Recipient gender } \\
\hline Male & 1101 & 178 & 1 & & \\
\hline Female & 744 & 107 & 0.88 & $0.69-1.12$ & 0.309 \\
\hline \multicolumn{6}{|l|}{ Type of allograft biopsy } \\
\hline One-year biopsy & 1541 & 189 & 1 & & \\
\hline Clinical indication biopsy in the $1^{\text {st }}$ year & 304 & 96 & 2.68 & $2.09-3.42$ & $<0.001$ \\
\hline $\begin{array}{l}\text { GFR (log transformed), per 1-mL/min } / 1.73 \mathrm{~m}^{2} \\
\text { increment }\end{array}$ & 1845 & 285 & 0.14 & $0.11-0.18$ & $<0.001$ \\
\hline $\begin{array}{l}\text { Proteinuria (square root value), per } 1-\mathrm{g} / \mathrm{g} \\
\text { increment }\end{array}$ & 1845 & 285 & 3.31 & $2.80-3.92$ & $<0.001$ \\
\hline \multicolumn{6}{|l|}{ Previous transplantation } \\
\hline No & 1511 & 210 & 1 & & \\
\hline Yes & 334 & 75 & 1.75 & $1.34-2.27$ & $<0.001$ \\
\hline \multicolumn{6}{|l|}{ Preemptive transplantation } \\
\hline No & 1603 & 277 & 1 & & \\
\hline Yes & 242 & 8 & 0.16 & $0.08-0.33$ & $<0.001$ \\
\hline Time since dialysis, per 1-year increment & 1603 & 277 & 1.03 & $1.00-1.05$ & 0.031 \\
\hline \multicolumn{6}{|l|}{ Donor gender } \\
\hline Male & 1008 & 150 & 1 & & \\
\hline Female & 837 & 135 & 1.09 & $0.87-1.38$ & 0.458 \\
\hline \multicolumn{6}{|l|}{ Donor type } \\
\hline Living & 336 & 33 & 1 & & \\
\hline Deceased & 1509 & 252 & 1.81 & $1.26-2.61$ & 0.001 \\
\hline Cold ischemia time, per 1 -hour increment & 1845 & 285 & 1.02 & $1.01-1.04$ & $<0.001$ \\
\hline $\begin{array}{l}\text { No. of HLA A/B/DR/DQ mismatch, per 1-unit } \\
\text { increment }\end{array}$ & 1845 & 285 & 1.02 & $0.92-1.12$ & 0.749 \\
\hline \multicolumn{6}{|l|}{ Pre-transplant anti-HLA DSA } \\
\hline No & 1503 & 200 & 1 & & \\
\hline Yes & 342 & 85 & 2.06 & $1.60-2.65$ & $<0.001$ \\
\hline \multicolumn{6}{|l|}{ Immunology } \\
\hline AT1R and HLA antibody status & & & & & $<0.001$ \\
\hline
\end{tabular}


$\begin{array}{llll}\text { None } & 1007 & 106 & 1\end{array}$

Anti-AT1R antibody

$371 \quad 60$

1.59

$1.16-2.18$

Donor-specific anti-HLA antibody

334

2.27

$1.69-3.05$

Anti-AT1R and donor-specific anti-HLA

133

3.88

2.74-5.50

antibody

\section{Histology}

Glomerulitis + Peritubular capillaritis

Banff score $\leq 1$

1546

186

299

99

1

Banff score $>1$

Interstitial inflammation + Tubulitis

Banff score $\leq 1$

$1528 \quad 211 \quad 1$

Banff score $>1$

317

74

1.75

$1.34-2.28$

$<0.001$

Intimal arteritis

Banff score 0

$1736 \quad 254 \quad 1$

Banff score $>0$

109

31

2.16

$1.53-3.08<0.001$

Chronic allograft glomerulopathy

Banff score 0

$1755 \quad 260 \quad 1$

Banff score $>0$

90

25

2.13

$1.41-3.22<0.001$

Interstitial fibrosis and tubular atrophy

Banff score $\leq 1$

$1354 \quad 178 \quad 1$

Banff score $>1$

491

107

1.83

$1.44-2.33$

$<0.001$

Arteriosclerosis

Banff score $\leq 1$

$1183 \quad 166 \quad 1$

Banff score $>1$

662

119

1.40

$1.10-1.76$

0.006

Arteriolar hyalinosis

Banff score $\leq 1$

1537

217

\section{1}

308

68

1.71

$1.30-2.25<0.001$

C4d deposition in peritubular capillaries

Banff score 0

$1660 \quad 225 \quad 1$

Banff score $>0$

185

$60 \quad 2.68$

2.02-3.57 $<0.001$

AT1R, angiotensin II type 1; Cl, confidence interval; GFR, glomerular filtration rate; HLA, human leukocyte antigen; HR, hazard ratio 
Table 3. Determinants of kidney allograft loss assessed at the time of antibody screening: Multivariable model.

\begin{tabular}{|c|c|c|c|c|c|}
\hline & $\begin{array}{c}\text { Number } \\
\text { of } \\
\text { patients }\end{array}$ & $\begin{array}{c}\text { Number } \\
\text { of } \\
\text { events }\end{array}$ & HR & $95 \% \mathrm{Cl}$ & $\mathbf{p}$ \\
\hline $\begin{array}{l}\text { GFR (log transformed), per 1- } \\
\mathrm{mL} / \mathrm{min} / 1.73 \mathrm{~m}^{2} \text { increment }\end{array}$ & 1845 & 285 & 0.21 & $0.16-0.29$ & $<0.001$ \\
\hline $\begin{array}{l}\text { Proteinuria (square root value), per } 1-\mathrm{g} / \mathrm{g} \\
\text { increment }\end{array}$ & 1845 & 285 & 2.25 & $1.85-2.73$ & $<0.001$ \\
\hline AT1R and HLA antibody status & & & & & $<0.001$ \\
\hline None & 1007 & 106 & 1 & & \\
\hline Anti-AT1R antibody & 371 & 60 & 1.49 & $1.07-2.06$ & \\
\hline Donor-specific anti-HLA antibody & 334 & 74 & 1.38 & $1.05-1.84$ & \\
\hline $\begin{array}{l}\text { Anti-AT1R and donor-specific anti- } \\
\text { HLA antibodies }\end{array}$ & 133 & 45 & 2.26 & $1.52-3.36$ & \\
\hline Glomerulitis + Peritubular capillaritis & & & & & \\
\hline Banff score $\leq 1$ & 1546 & 186 & 1 & & \\
\hline Banff score $>1$ & 299 & 99 & 1.79 & $1.32-2.43$ & $<0.001$ \\
\hline Interstitial fibrosis and tubular atrophy & & & & & \\
\hline Banff score $\leq 1$ & 1354 & 178 & 1 & & \\
\hline Banff score $>1$ & 491 & 107 & 1.29 & $1.00-1.67$ & 0.046 \\
\hline
\end{tabular}


Table 4. Kidney allograft injury according to the presence of circulating anti-angiotensin II type 1 receptor antibodies.

Data are based on 1845 kidney transplant recipients who were assessed simultaneously for the presence of circulating anti-AT1R antibodies and kidney allograft histology within the first year after transplantation. Histological assessment of kidney allograft injury was performed according to the Banff classification for allograft rejection. Each individual lesion was considered present (Banff score of 1,2 or 3 ) or absent (Banff score of 0 ). Pathological features of active antibody-mediated rejection were defined by microcirculation inflammation with the sum of glomerulitis and peritubular capillaritis Banff scores $>1$ according to the Banff classification.

\begin{tabular}{|c|c|c|c|c|}
\hline & $\begin{array}{l}\text { Overall } \\
(n=1845)\end{array}$ & $\begin{array}{l}\text { AT1R-Ab } \\
\text { negative } \\
(\mathrm{n}=1341)\end{array}$ & $\begin{array}{l}\text { AT1R-Ab } \\
\text { positive } \\
(n=504)\end{array}$ & $\mathbf{p}$ \\
\hline Type of allograft biopsy, No. (\%) & & & & 0.262 \\
\hline Clinical indication biopsy & $304(16.5)$ & $213(15.9)$ & $91(18.1)$ & \\
\hline One-year protocol biopsy & $1541(83.5)$ & $1128(84.1)$ & $413(81.9)$ & \\
\hline Glomerulitis, No. (\%) & $424(23.0)$ & $277(20.7)$ & $147(29.2)$ & $<0.001$ \\
\hline Peritubular capillaritis, No. (\%) & $377(20.4)$ & $232(17.3)$ & $145(28.8)$ & $<0.001$ \\
\hline Interstitial inflammation, No. (\%) & $393(21.3)$ & $281(21.0)$ & $112(22.2)$ & 0.553 \\
\hline Tubulitis, No. (\%) & $381(20.7)$ & $269(20.1)$ & $112(22.2)$ & 0.307 \\
\hline Intimal arteritis, No. (\%) & $109(5.9)$ & $53(4.0)$ & $56(11.1)$ & $<0.001$ \\
\hline $\begin{array}{l}\text { Chronic allograft glomerulopathy, No. } \\
(\%)\end{array}$ & $90(4.9)$ & $58(4.3)$ & $32(6.4)$ & 0.072 \\
\hline $\begin{array}{l}\text { Interstitial fibrosis and tubular } \\
\text { atrophy, No. (\%) }\end{array}$ & $1095(59.4)$ & $789(58.8)$ & $306(60.7)$ & 0.464 \\
\hline Arteriosclerosis, No. (\%) & 1187 (64.3) & $872(65.0)$ & $315(62.5)$ & 0.313 \\
\hline Arteriolar hyalinosis, No. (\%) & $1084(58.8)$ & $794(59.2)$ & $290(57.5)$ & 0.516 \\
\hline C4d deposition, No. (\%) & $185(10.0)$ & $125(9.3)$ & $60(11.9)$ & 0.100 \\
\hline $\begin{array}{l}\text { Pathological features of ABMR with } \\
\text { donor-specific anti-HLA antibodies, } \\
\text { No. }(\%)\end{array}$ & $222(12.0)$ & $147(11.0)$ & $75(14.8)$ & 0.021 \\
\hline $\begin{array}{l}\text { Pathological features of ABMR without } \\
\text { donor-specific anti-HLA antibodies, } \\
\text { No. (\%) }\end{array}$ & $77(4.2)$ & $26(1.9)$ & $51(10.1)$ & $<0.001$ \\
\hline T-cell mediated rejection, No. (\%) & $182(9.9)$ & $128(9.6)$ & $54(10.7)$ & 0.453 \\
\hline
\end{tabular}

Ab, antibody; ABMR, active antibody-mediated rejection; AT1R, angiotensin II type 1 receptor; HLA, human leukocyte antigen 
Table 5. Kidney allograft injury according to the presence of post-transplant circulating anti-angiotensin II type 1 receptor antibodies and circulating donor-specific anti-HLA antibodies in patients with histological features of active antibody-mediated rejection.

Data are based on 1845 kidney allograft biopsies performed within the first year after transplantation, in which $299(16.2 \%)$ showed histological features of active antibody-mediated rejection (sum of glomerulitis and peritubular capillaritis Banff scores $>1$ ). Histological assessment of kidney allograft injury was performed according to the Banff classification for allograft rejection. Each individual lesion was considered present (Banff score of 1,2 or 3) or absent (Banff score of $0)$.

\begin{tabular}{|c|c|c|c|c|c|c|}
\hline & $\begin{array}{l}\text { Overall } \\
(n=299)\end{array}$ & $\begin{array}{c}\text { AT1R-Ab- } \\
\text { HLA-DSA- } \\
(n=26)\end{array}$ & $\begin{array}{c}\text { AT1R-Ab+ } \\
\text { HLA-DSA- } \\
(n=51)\end{array}$ & $\begin{array}{c}\text { AT1R-Ab- } \\
\text { HLADSA+ } \\
(n=147)\end{array}$ & $\begin{array}{c}\text { AT1R-Ab+ } \\
\text { HLADSA+ } \\
(n=75)\end{array}$ & $\mathbf{p}$ \\
\hline Type of allograft biopsy, No. (\%) & & & & & & 0.001 \\
\hline Clinical indication biopsy & $175(58.5)$ & $7(26.9)$ & $29(56.9)$ & $84(57.1)$ & $55(73.3)$ & \\
\hline One-year protocol biopsy & $124(41.5)$ & $19(73.1)$ & $22(43.1)$ & $63(42.9)$ & $20(26.7)$ & \\
\hline Glomerulitis, No. (\%) & $285(95.3)$ & $22(84.6)$ & $49(96.1)$ & $141(95.9)$ & $73(97.3)$ & 0.094 \\
\hline Peritubular capillaritis, No. (\%) & $285(95.3)$ & $20(76.9)$ & $49(96.1)$ & $141(95.9)$ & $75(100)$ & $<0.001$ \\
\hline Interstitial inflammation, №. (\%) & $117(39.1)$ & $12(46.2)$ & $21(41.2)$ & $57(38.8)$ & $27(36.0)$ & 0.805 \\
\hline Tubulitis, No. (\%) & $102(34.1)$ & $8(30.8)$ & $21(41.2)$ & $49(33.3)$ & $21(28.0)$ & 0.484 \\
\hline Intimal arteritis, No. (\%) & $59(19.7)$ & $3(11.5)$ & $22(43.1)$ & $18(12.2)$ & $16(21.3)$ & $<0.001$ \\
\hline Chronic allograft glomerulopathy, No. (\%) & $50(16.7)$ & $2(7.7)$ & $6(11.8)$ & $26(17.7)$ & $16(21.3)$ & 0.338 \\
\hline $\begin{array}{l}\text { Interstitial fibrosis and tubular atrophy, No. } \\
(\%)\end{array}$ & $219(73.2)$ & $14(53.9)$ & $41(80.4)$ & $108(73.5)$ & $56(74.7)$ & 0.111 \\
\hline Arteriosclerosis, No. (\%) & $202(67.6)$ & $17(65.4)$ & $31(60.8)$ & $100(68.0)$ & $54(72.0)$ & 0.598 \\
\hline Arteriolar hyalinosis, No. (\%) & $173(57.9)$ & $15(57.7)$ & $32(62.8)$ & $88(59.9)$ & $38(50.7)$ & 0.509 \\
\hline C4d deposition, No. (\%) & $121(40.5)$ & $2(7.7)$ & $7(13.7)$ & $73(49.7)$ & $39(52.0)$ & $<0.001$ \\
\hline
\end{tabular}

Ab, antibody; AT1R, angiotensin II type 1 receptor; DSA, donor-specific antibody; HLA, human leukocyte antigen 


\section{FIGURE LEGENDS}

Figure 1. Kaplan-Meier curves for death-censored kidney allograft survival after antibody screening according to post-transplant circulating anti-angiotensin II type 1 receptor antibody status.

Data are based on 1845 kidney transplant recipients undergoing systematic screening for circulating donor-specific anti-HLA antibodies and anti-angiotensin II type 1 receptor antibodies within the first year after transplantation. Panel A shows Kaplan-Meier curves for death-censored kidney allograft survival on the basis of the presence of post-transplant anti-angiotensin II type 1 receptor antibodies. Panel B shows Kaplan-Meier curves for death-censored kidney allograft survival according to post-transplant anti-angiotensin II type 1 receptor antibody status and posttransplant donor-specific anti-HLA antibody status.

Ab, antibody; AT1R, angiotensin II type 1 receptor; DSA, donor-specific antibody; HLA, human leukocyte antigen

Figure 2. Risk of occurrence of microcirculation and arterial injury according to posttransplant circulating anti-angiotensin II type 1 receptor antibody level.

Data are based on 1845 kidney transplant recipients who were assessed simultaneously for the presence of circulating anti-AT1R antibodies and kidney allograft histology within the first year after transplantation. The blue curve represents the relationship between circulating anti-AT1R antibody level and the risk of occurrence of glomerulitis (Panel A), peritubular capillaritis (Panel $B$ ) and intimal arteritis (Panel C) in allografts on the basis of penalized splines. Dashed lines denote 95\% confidence intervals. The grey bars represent individual anti-AT1R antibody levels. The spline curves were truncated at anti-AT1R antibody level of $20 \mathrm{U} / \mathrm{mL}$ given the low number of patients above this value $(n=74 / 1845,4.0 \%)$. Significant odds ratios are observed from AT1R antibody levels between 10 and $15 \mathrm{U} / \mathrm{mL}$ for glomerulitis (A), peritubular capillaritis (B) and intimal arteritis (C), where the lower limit of the $95 \%$ confidence intervals are above an odds ratio of 1 (red line).

AT1R, angiotensin II type 1 receptor; OR, odds ratio

Figure 3. Complement-independent antibody-mediated vascular kidney allograft rejection in patients with circulating anti-angiotensin II type 1 receptor antibodies.

Data are based on 1845 kidney transplant recipients who were assessed simultaneously for the presence of circulating anti-angiotensin II type 1 receptor antibodies and kidney allograft histology within the first year after transplantation, in whom 299 (16.2\%) showed histological features of active antibody-mediated rejection according to the Banff classification for allograft rejection (microcirculation inflammation with sum of glomerulitis and peritubular capillaritis Banff scores $>1$ ). Among patients with histological features of active antibody-mediated rejection, $51(17.0 \%)$ had anti-angiotensin II type 1 receptor antibodies, 147 (49.2\%) had donor-specific anti-HLA antibodies, $75(25.1 \%)$ had both antibodies and $26(8.7 \%)$ had no antibody. Anti-angiotensin II type 1 receptor antibody-associated rejection was characterized by vascular inflammation with microvascular and arterial inflammation, endothelial activation reflected by high levels of expression of endothelialassociated transcripts, and lack of complement deposition in allograft capillaries. (A) Severe intimal arteritis in a patient with anti-angiotensin II type 1 receptor antibody-associated rejection characterized by subendothelial infiltration of an interlobular artery by inflammatory cells; Masson's trichrome stain, original magnification $\times 200$, bar $=200 \mu \mathrm{m}$. (B). Peritubular capillaritis and lack of complement fraction $\mathrm{C} 4 \mathrm{~d}$ deposition in peritubular capillaries in the same patient with anti- 
angiotensin II type 1 receptor antibody-associated rejection; immunoperoxidase, original magnification $x 400$, bar $=200 \mu \mathrm{m}$. (C). Expression levels of endothelial-associated transcripts (ENDATs) in patients with features of active antibody-mediated rejection according to antiangiotensin II type 1 receptor antibody and donor-specific anti-HLA antibody status. Expression levels of ENDATs were measured using microarray. ENDATs represent a pathogenesis-based transcript set that reflects endothelial activation and indicates current/recent antibody interaction with the vascular endothelium.

Ab, antibody; AT1R, angiotensin II type 1 receptor; DSA, donor-specific antibody; HLA, human leukocyte antigen 
A
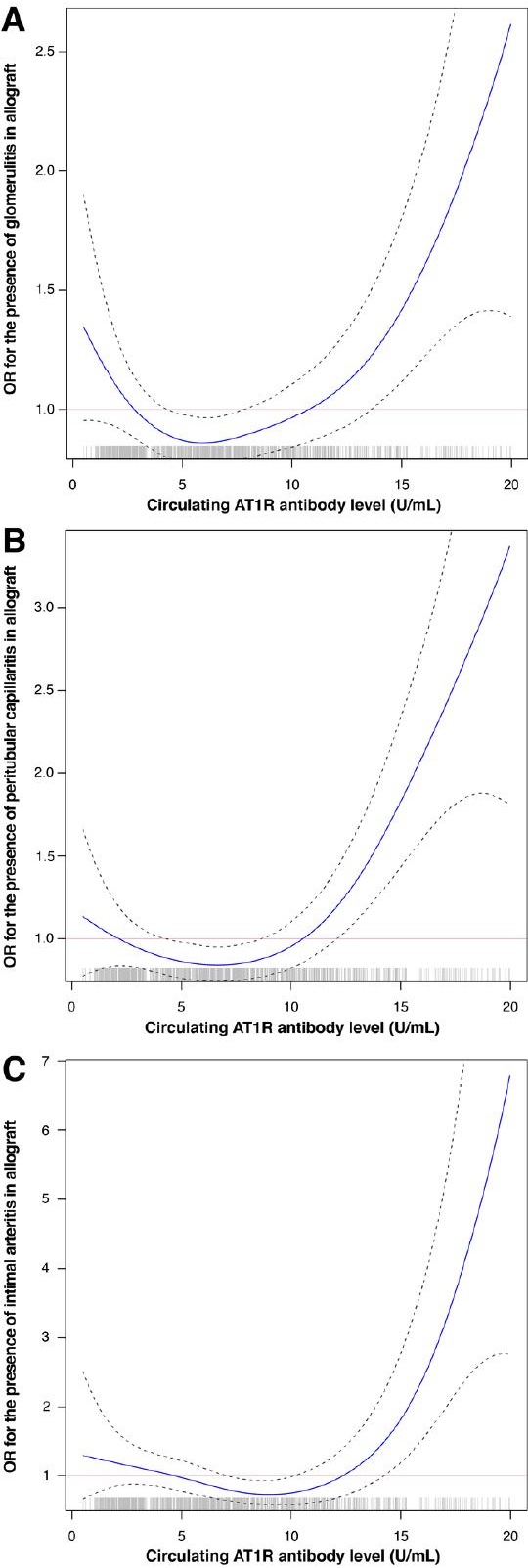

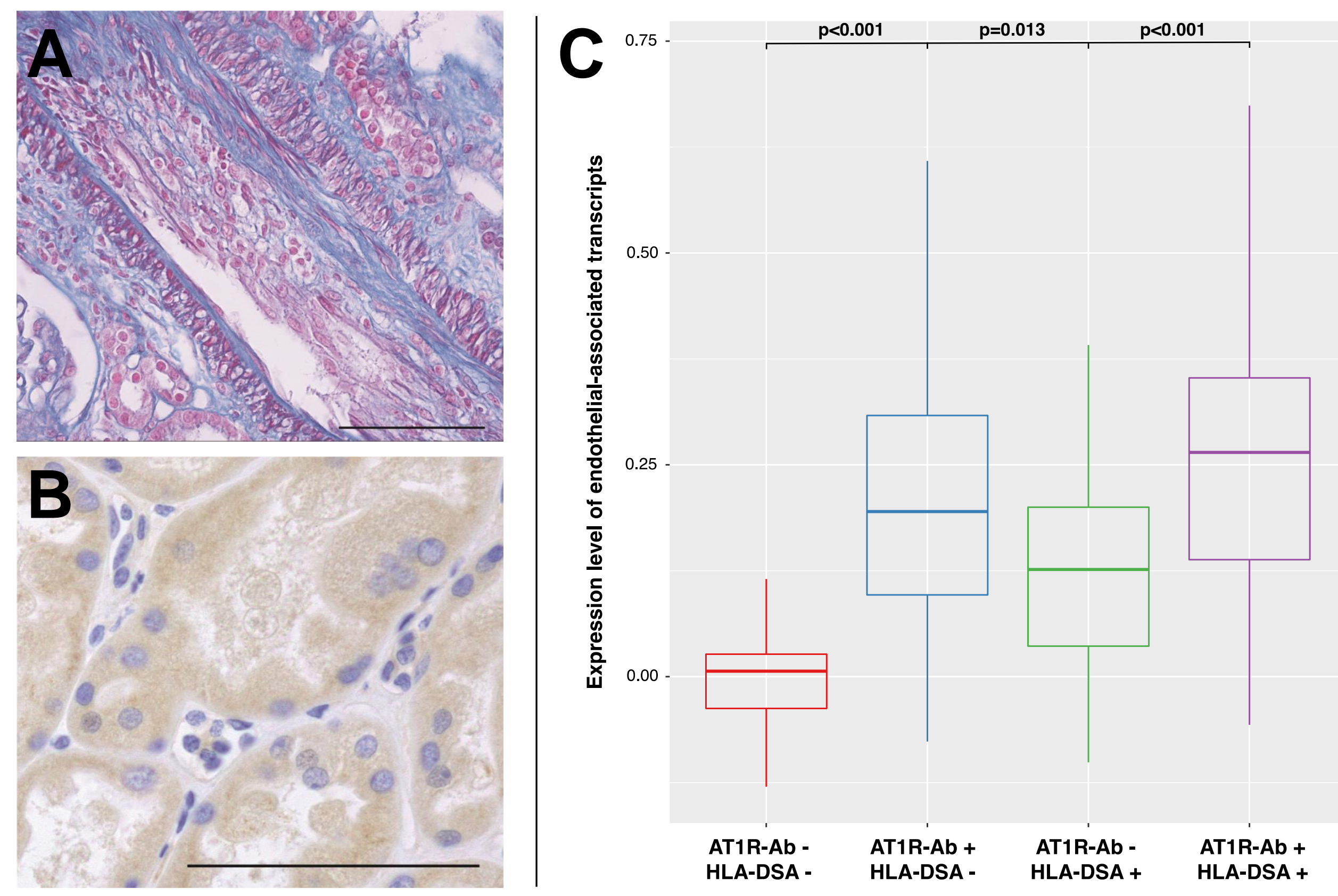
Non-HLA Agonistic Anti-Angiotensin II Type 1 Receptor Antibodies Induce a Distinctive Phenotype of Antibody-mediated Rejection in Kidney Transplant Recipients

\section{Prospective} cohort minin

1845 kidney transplant patients

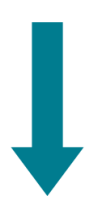

Allograft evaluation within the $1^{\text {st }}$ yr post-tx

- AT1R Abs

- HLADSAs

- Graft function

- Graft biopsy
AT1R Ab-associated C4dnegative vascular rejection
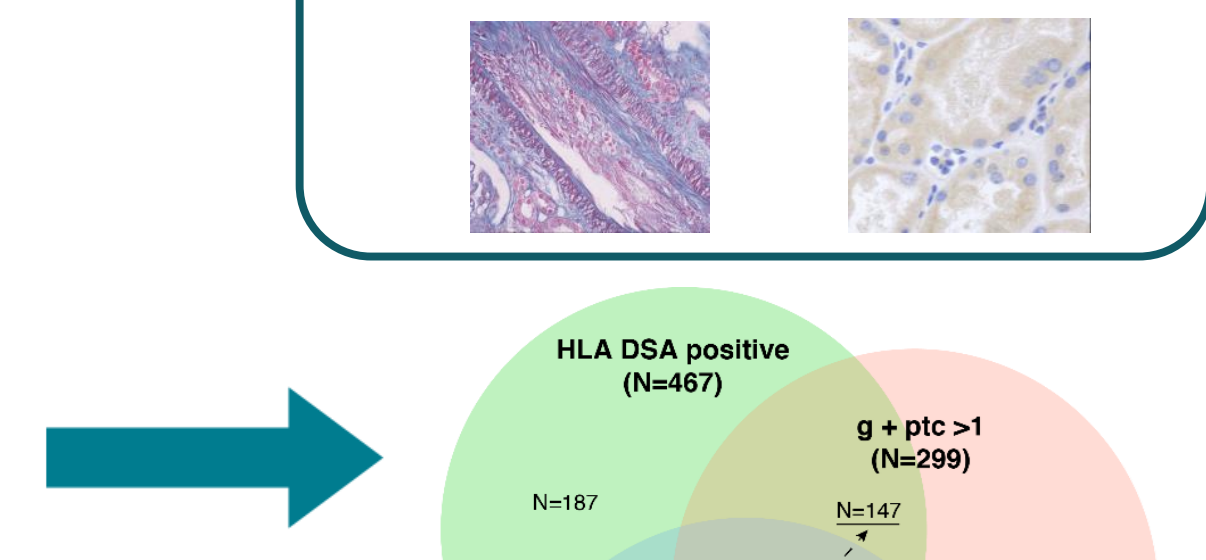

( $N=467)$

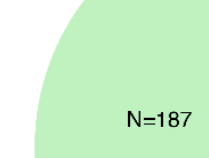

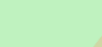

$\mathrm{g}+\mathrm{ptc}>1$

$\mathrm{N}=147$

$\mathrm{N}=26$
$\mathrm{N}=320$

AT1R-Ab positive $(\mathrm{N}=504)$

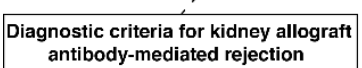

$=51$
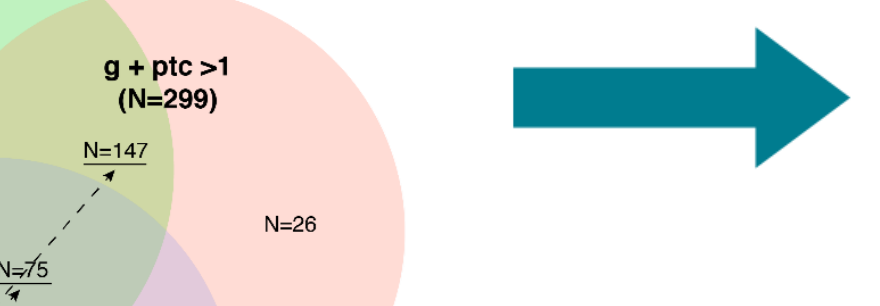

Reclassified rejection cases based on
the detection of circulating AT1R Ab
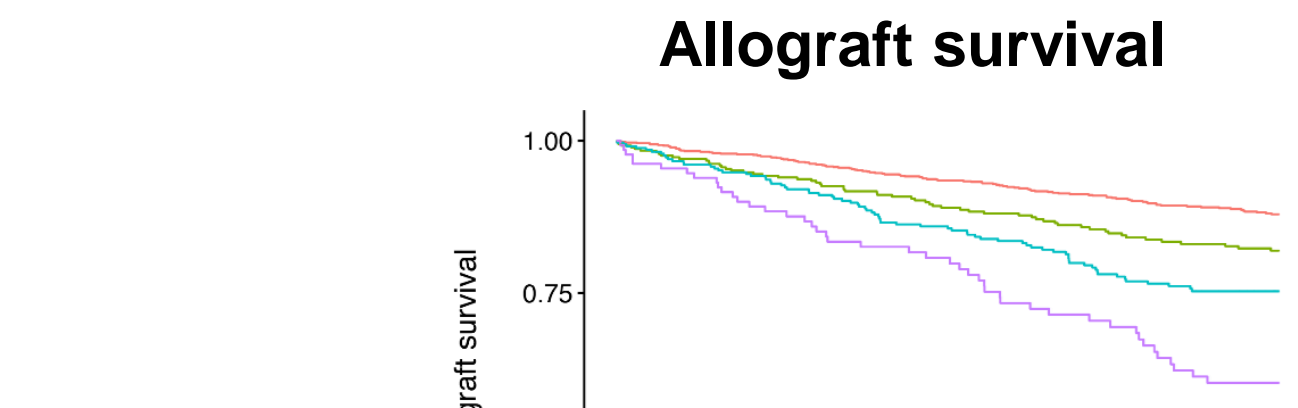

AT1R-Ab negative/HLA-DSA negative - AT1R-Ab positive/HLA-DSA negative

AT1R-Ab negative/HLA-DSA positive

- AT1R-Ab positive/HLA-DSA positive
Number at risk

$\begin{array}{lllllllll}\text { AT1R-Ab negative/HLA-DSA negative } & 1007 & 953 & 915 & 852 & 792 & 740 & 683 & 589\end{array}$ $\begin{array}{llllllllll}\text { AT1R-Ab positive/HLA-DSA negative } & 371 & 349 & 332 & 303 & 283 & 251 & 236 & 207\end{array}$ $\begin{array}{lllllllll}\text { AT1R-Ab negative/HLA-DSA positive } & 334 & 311 & 295 & 266 & 241 & 214 & 191 & 145\end{array}$ $\begin{array}{lllllllll}\text { AT1R-Ab positive/HLA-DSA positive } & 133 & 120 & 105 & 96 & 81 & 70 & 61 & 50\end{array}$

\section{CONCLUSION:}

Circulating AT1R Abs associate with a specific kidney allograft rejection phenotype and graft loss, independent of the HLA system. 